\title{
Photodecarbonylation of 1,3-Dithiophenyl Propanone: Using \\ Nanocrystals to Overcome the Filtering Effect of Highly Absorbing \\ Trace Impurities
}

Marino J. E. Resendiz, Jennifer Taing and Miguel A. Garcia-Garibay*

Department of Chemistry and Biochemistry, University of California-Los Angeles, 405 Hilgard Avenue, Los Angeles, California 90095-1569. E-mail: mgg@chem.ucla.edu; Fax: 310-825-6707; Tel: 310-825-3159.

\section{Supporting Information}

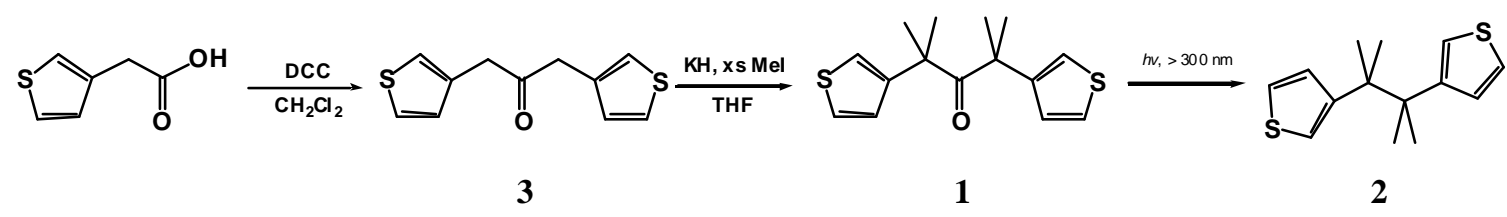

\section{Experimental}

Materials. Tetrahydrofuran (THF) was dried by distillation from the sodium ketyl of benzophenone, $\mathrm{CH}_{2} \mathrm{Cl}_{2}$ was dried by distillation from $\mathrm{CaH}_{2}$. All other reagents were commercial products that were used without further purification. Gas chromatography (GC) was conducted on a $0.2 \mathrm{~mm} \times 25 \mathrm{~m} \times 0.11 \mu \mathrm{m}$ HP-1 (cross linked methyl silicon gum) capillary column. IR spectra were obtained with a Perkin-Elmer Spectrum 100 Series spectrometer (neat). ${ }^{1} \mathrm{H}$ and ${ }^{13} \mathrm{C}$ NMR spectra were recorded at 500 and $125 \mathrm{MHz}$ respectively with a Bruker ARX 500 and Avance 500 spectrometers in $\mathrm{CDCb}_{3}$ and $\mathrm{C}_{6} \mathrm{D}_{6}$. Powder X-RD's were recorded on a Rigaku RINT 2100 X-ray diffractometer. Melting points were determined in a Barnstead/Thermolyne Melt-Temp II apparatus. Differential 
Scanning Calorimetry (DSC) experiments were recorded on a Perkin Elmer PYRIS Diamond Instrument.

General Procedure for Photolysis in Benzene. Compound 1 was dissolved in anhydrous benzene $\left(10^{-3} \mathrm{M}\right)$ and deoxygenated by bubbling Argon for $30 \mathrm{~min}$. Samples were taken at different time intervals and monitored by GC and NMR until disappearance of the starting material.

General Procedure for Photolysis in the Solid State. Finely powdered solid samples of $1(\sim 60 \mathrm{mg})$ were placed evenly on a Petri dish at a distance $(\sim 10 \mathrm{~cm})$ from a mediumpressure Hg Hanovia lamp. During the course of irradiation, small amounts of each sample were removed at various times and analyzed by GC, NMR and X-RPD.

\section{Synthesis of 1,3-di(thiophen-3-yl)propan-2-one $\quad 3 .{ }^{1} \quad$ A solution of} dicyclohexylcarbodiimide $(0.330 \mathrm{~g}, 1.6 \mathrm{mmol})$ and 4-(dimethylamino)pyridine $(0.048 \mathrm{~g}$, $0.4 \mathrm{mmol})$ in $\mathrm{CH}_{2} \mathrm{Cl}_{2}(50 \mathrm{~mL})$ was stirred at room temperature under Argon and treated dropwise with a solution of the respective acetic acid $(0.227 \mathrm{~g}, 1.6 \mathrm{mmol})$ in $\mathrm{CH}_{2} \mathrm{Cl}_{2}(10$ $\mathrm{mL}$ ). The resulting mixture (orange) was stirred at room-temperature for 3 hours followed by removal of the precipitate by filtration. Volatiles were removed from the filtrate by evaporation under reduced pressure. Purification of the residue by flash chromatography (silica, $\mathrm{CH}_{3} \mathrm{COOC}_{2} \mathrm{H}_{5}=20 \%$, hexanes $=80 \%$ ) resulted in a white crystalline powder of $3 \mathrm{mp} 45-47^{\circ} \mathrm{C}(73 \%)$; ? $?_{\max }(\mathrm{MeCN}) 229 ;{ }^{1} \mathrm{H} \mathrm{NMR}\left(\mathrm{CDCl}_{3}\right) 7.34$ $(\mathrm{dd}, J=4.92 \mathrm{~Hz}, 1 \mathrm{H}), 7.11(\mathrm{~d}, J=2.3 \mathrm{~Hz}, 1 \mathrm{H}), 6.97(\mathrm{dd}, J=4.92 \mathrm{~Hz}, 1 \mathrm{H}) 3.81(\mathrm{~s}, 2 \mathrm{H})$ ppm; ${ }^{13} \mathrm{C}$ NMR $\left(\mathrm{CDCl}_{3}\right)$ 204.7, 133.5, 128.4, 125.9, 123, 43.3 ppm; IR (neat) 1709, 1531, $1388,1080,1055 \mathrm{~cm}^{-1}$; GC-MS (EI) $\mathrm{m} / z$ calculated for $\mathrm{C}_{11} \mathrm{H}_{10} \mathrm{OS}_{2}, 222.03$, found $\mathrm{m} / z=$ $222.0\left(\mathrm{M}^{*+}\right), 194,125,97$. 
Synthesis of 2,4-dimethyl-2,4-di(thiophen-3-yl)pentan-3-one 1. Ketone 3 ( $0.350 \mathrm{~g}$, $1.57 \mathrm{mmol})$ dissolved in $15 \mathrm{~mL}$ dry THF was added dropwise to a cooled solution $\left(0^{\circ} \mathrm{C}\right)$ of potassium hydride $(0.5 \mathrm{~g}, 12.2 \mathrm{mmol})$ in $30 \mathrm{~mL}$ THF. Methyl Iodide was added (0.4 $\mathrm{mL}, 6.4 \mathrm{mmol}$ ) dropwise to the yellow suspension and stirred to room temperature. The suspension turned white and then was refluxed until it an orange color was observed, consequently, the suspension was cooled to $0^{\circ} \mathrm{C}$ and an additional amount of iodomethane $(0.15 \mathrm{~mL}, 2.4 \mathrm{mmol})$ was added dropwise followed by extractions with water and diethyl ether. The ether layer was dried over $\mathrm{MgSO}_{4}$ and evaporated under reduced pressure. Purification of the residue by column chromatography (silica, $\mathrm{CH}_{3} \mathrm{COOC}_{2} \mathrm{H}_{5}=10 \%$, hexanes $=90 \%)$ resulted in a white crystalline powder of 1 with mp $76-78^{\circ} \mathrm{C}(90 \%)$; ? max $(\mathrm{MeCN}) 238 ;{ }^{1} \mathrm{H} \mathrm{NMR}\left(\mathrm{CDCl}_{3}\right) 7.17(\mathrm{dd}, J=4.96 \mathrm{~Hz}, 1 \mathrm{H}), 6.84(\mathrm{~d}, J=2.9 \mathrm{~Hz}, 1 \mathrm{H}), 6.76$ $(\mathrm{dd}, J=4.96 \mathrm{~Hz}, 1 \mathrm{H}) 1.36(\mathrm{~s}, 6 \mathrm{H}) \mathrm{ppm} ;{ }^{13} \mathrm{C} \mathrm{NMR}\left(\mathrm{CDCl}_{3}\right) 211.8,146,126.6,125.1$, 119.6, 50.8 and $27.7 \mathrm{ppm}$; IR (neat) 1682, 1469, 1385, 1366, $1030 \mathrm{~cm}^{-1}$; GC-MS (EI) $\mathrm{m} / \mathrm{z}$ calculated for $\mathrm{C}_{15} \mathrm{H}_{18} \mathrm{OS}_{2}, 278.1$, found $m / z=278.0\left(\mathrm{M}^{*+}\right), 125,109,97,85$.

3-(2,3-dimethyl-3-(thiophen-3-yl)butan-2-yl)thiophene $2 .{ }^{2}$ Compound 2 was purified from combining various solid-state photolyses at low conversions (7-15\%) of polycrystalline samples from the $\mathbf{1}$ ? $\mathbf{2}$ transformation through column chromatography using hexanes as the eluent. Compound $\mathbf{2}$ was obtained as a white solid with mp 125$128^{\circ} \mathrm{C}$. Alternatively, to a solution of thiophenyl ketone $1(0.04 \mathrm{~g}, 0.14 \mathrm{mmol})$ in acetone ( $2 \mathrm{~mL}) 10 \mathrm{~mL}$ of a water/SDS solution $(2.5 \mathrm{mM})$ is added at once. Air is blown onto the reaction vial while stirring it until a total volume of $6 \mathrm{~mL}$ is obtained, after; extra $2 \mathrm{~mL}$ of water are added to make a total volume of $8 \mathrm{~mL}$. The milky white suspension is placed at a distance $(\sim 10 \mathrm{~cm})$ from a medium-pressure Hg Hanovia lamp and stir while keeping a 
constant temperature inside the photolysis chamber $\left(\mathrm{ca} .25^{\circ} \mathrm{C}\right)$. During the course of irradiation, small amounts of each sample were removed at various times and analyzed by GC, NMR and X-RPD. Irradiation stopped at 12 hours followed by filtration of the yellowish precipitate yielded 2 as a solid. ${ }^{1} \mathrm{H}$ NMR $\left(\mathrm{CDCl}_{3}\right) 7.14(\mathrm{dd}, J=3.0,4.98 \mathrm{~Hz}$, $1 \mathrm{H}), 6.79(\mathrm{dd}, J=3 . \mathrm{Hz}, 1 \mathrm{H}), 6.77(\mathrm{dd}, J=4.98 \mathrm{~Hz}, 1 \mathrm{H}) 1.34(\mathrm{~s}, 6 \mathrm{H}) \mathrm{ppm} ;{ }^{13} \mathrm{C} \mathrm{NMR}$ $\left(\mathrm{CDCl}_{3}\right) 148.8,128.7,122.4,120.9,42.3$ and $25.3 \mathrm{ppm}$; IR (neat) 1452, 1368, 1083 and $859 \mathrm{~cm}^{-1}$. 


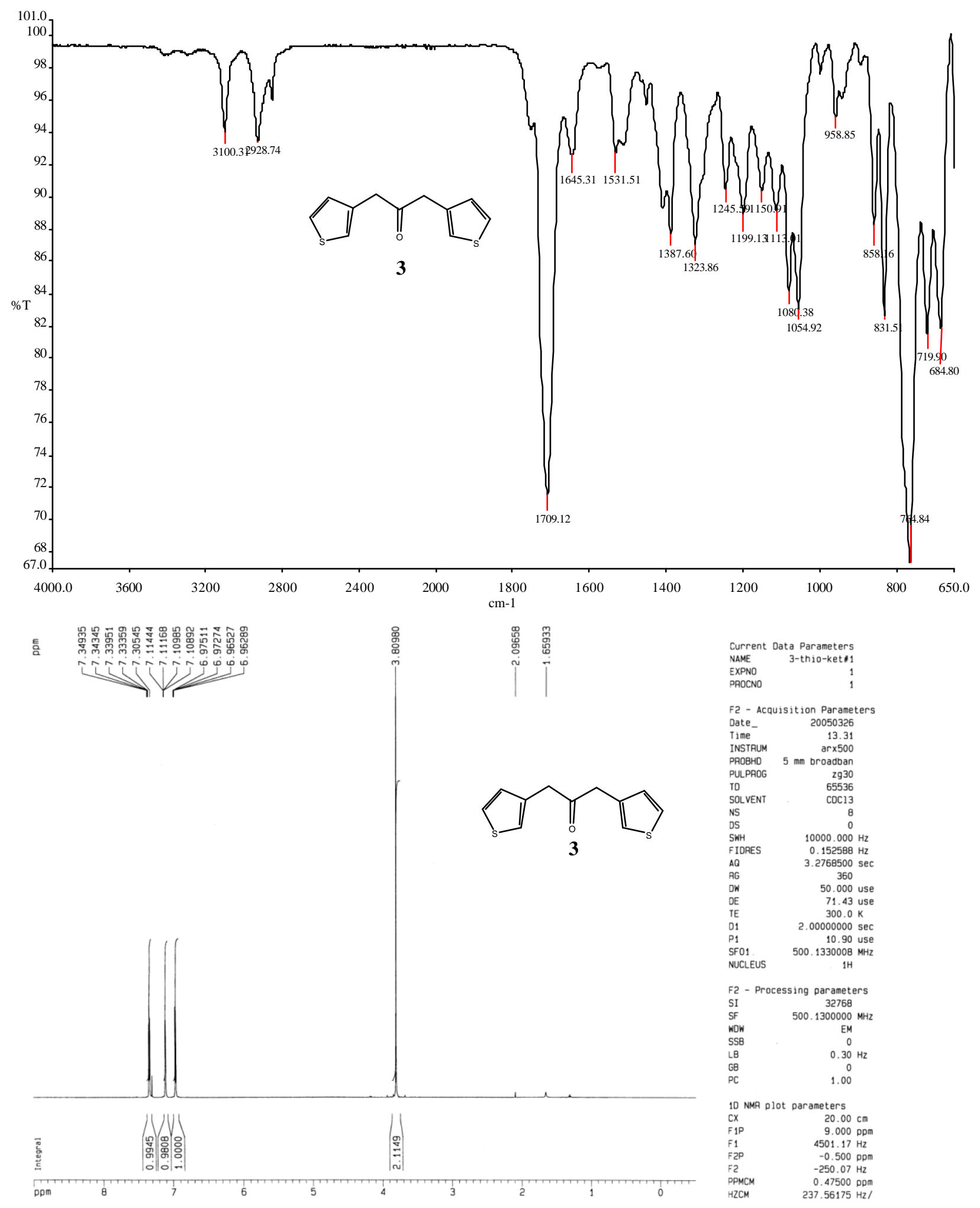



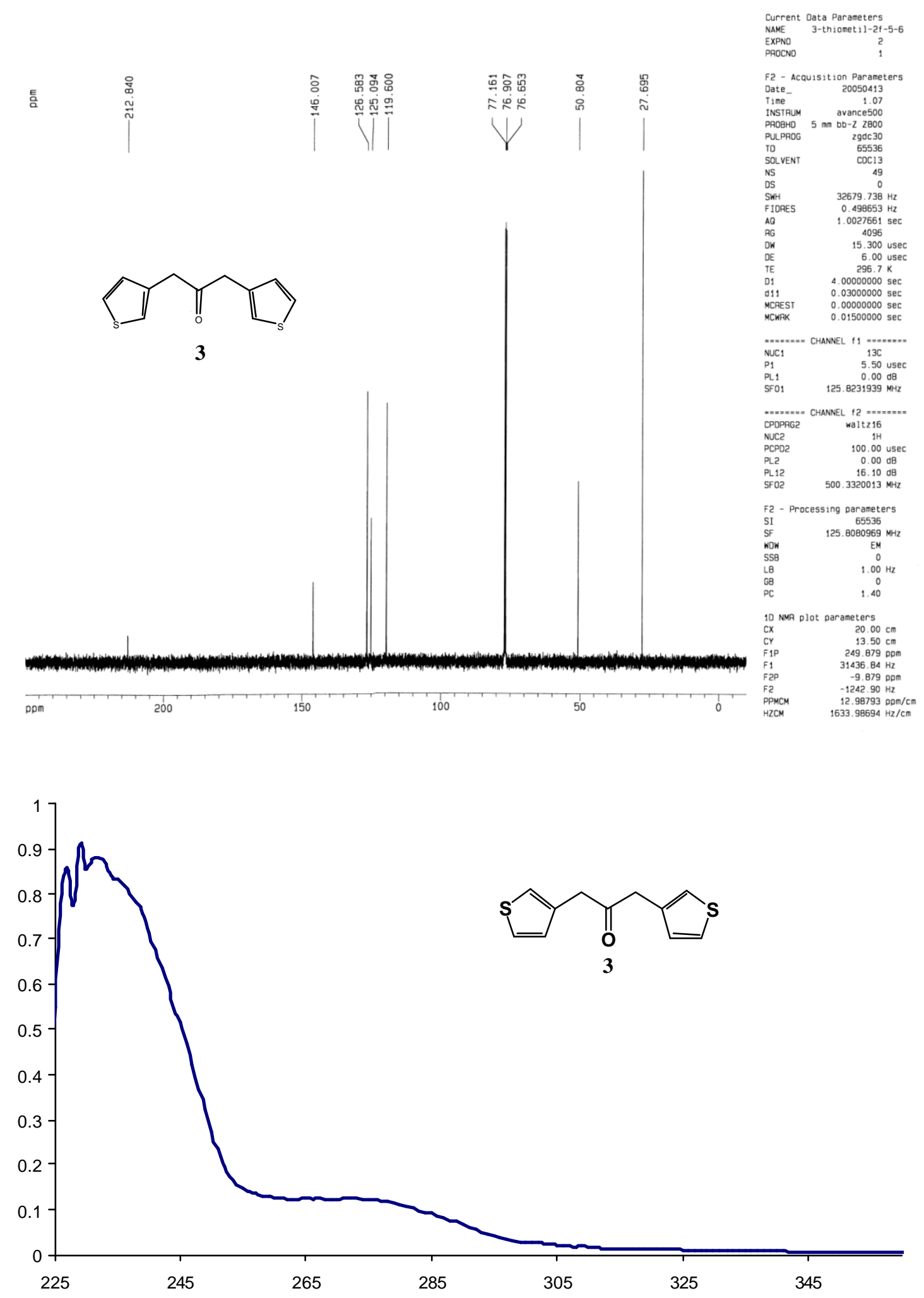


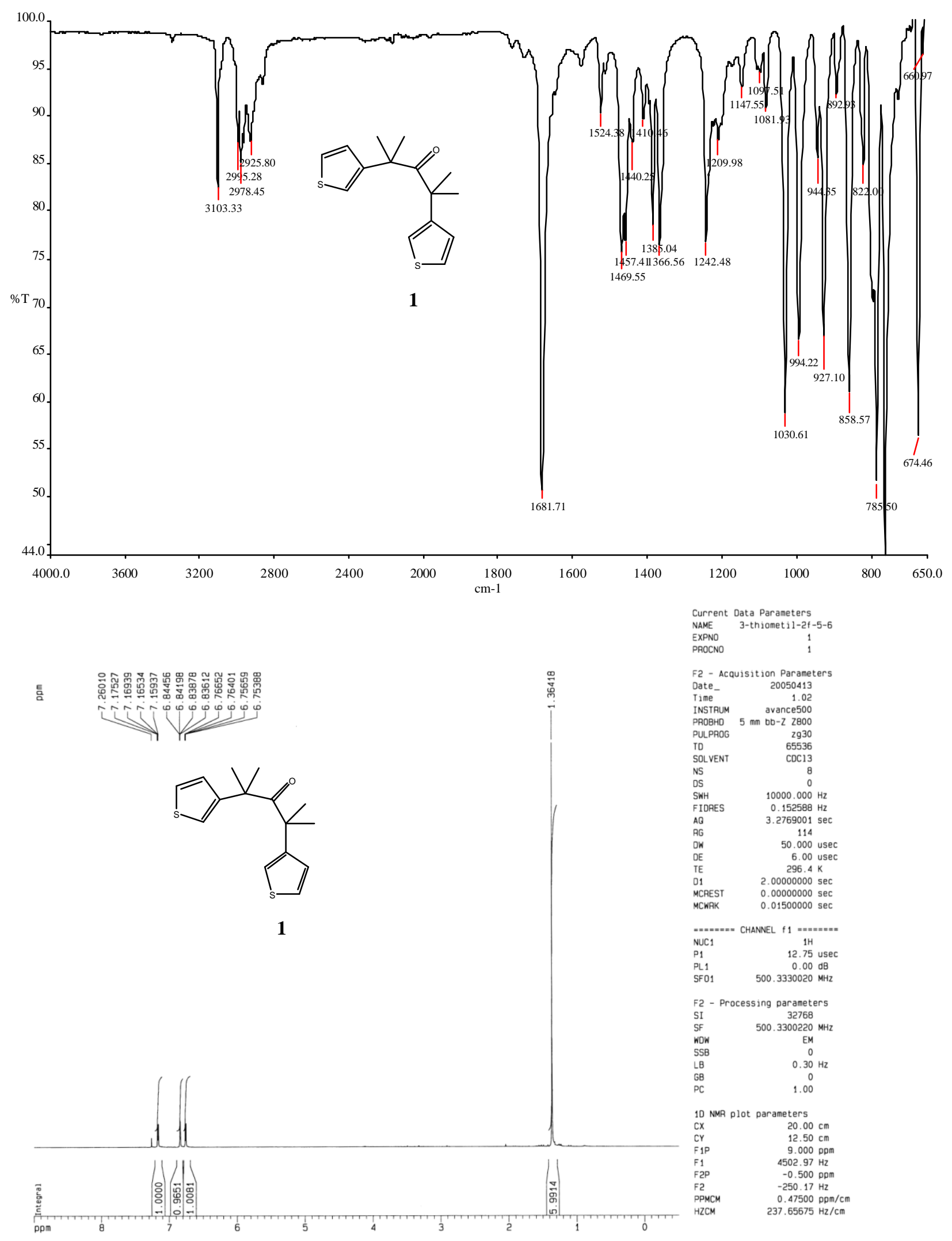



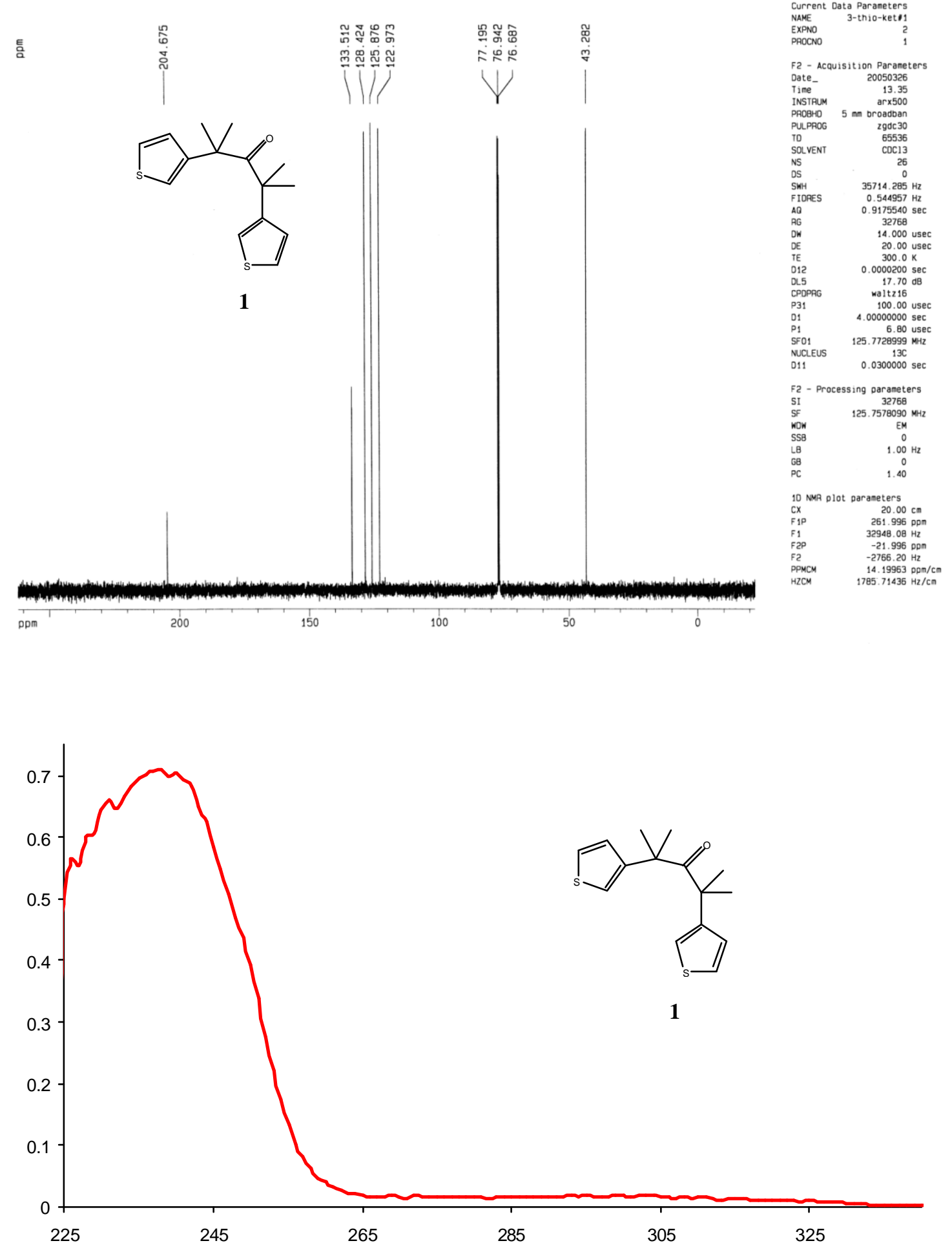

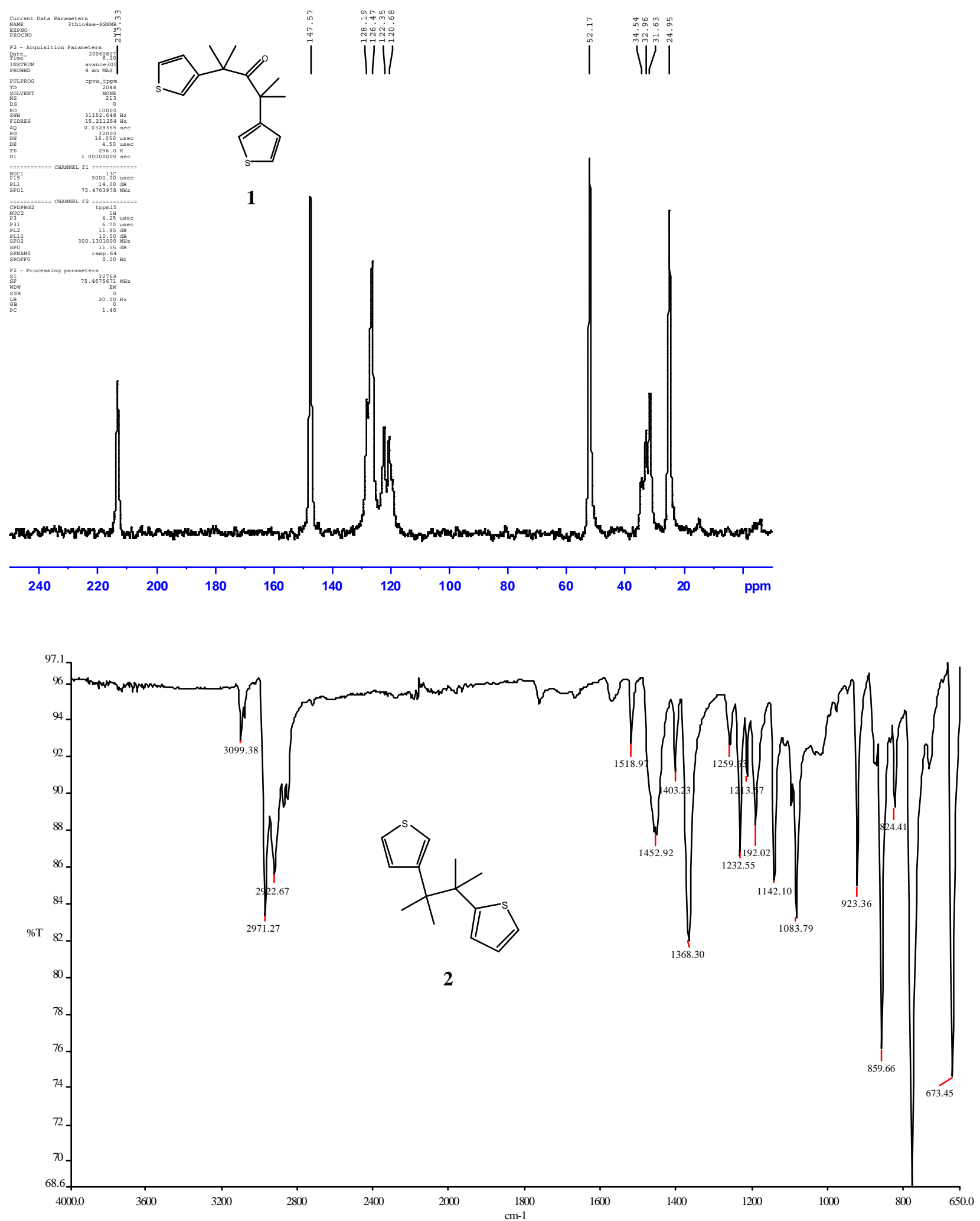


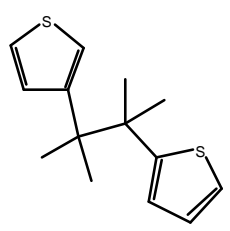

2
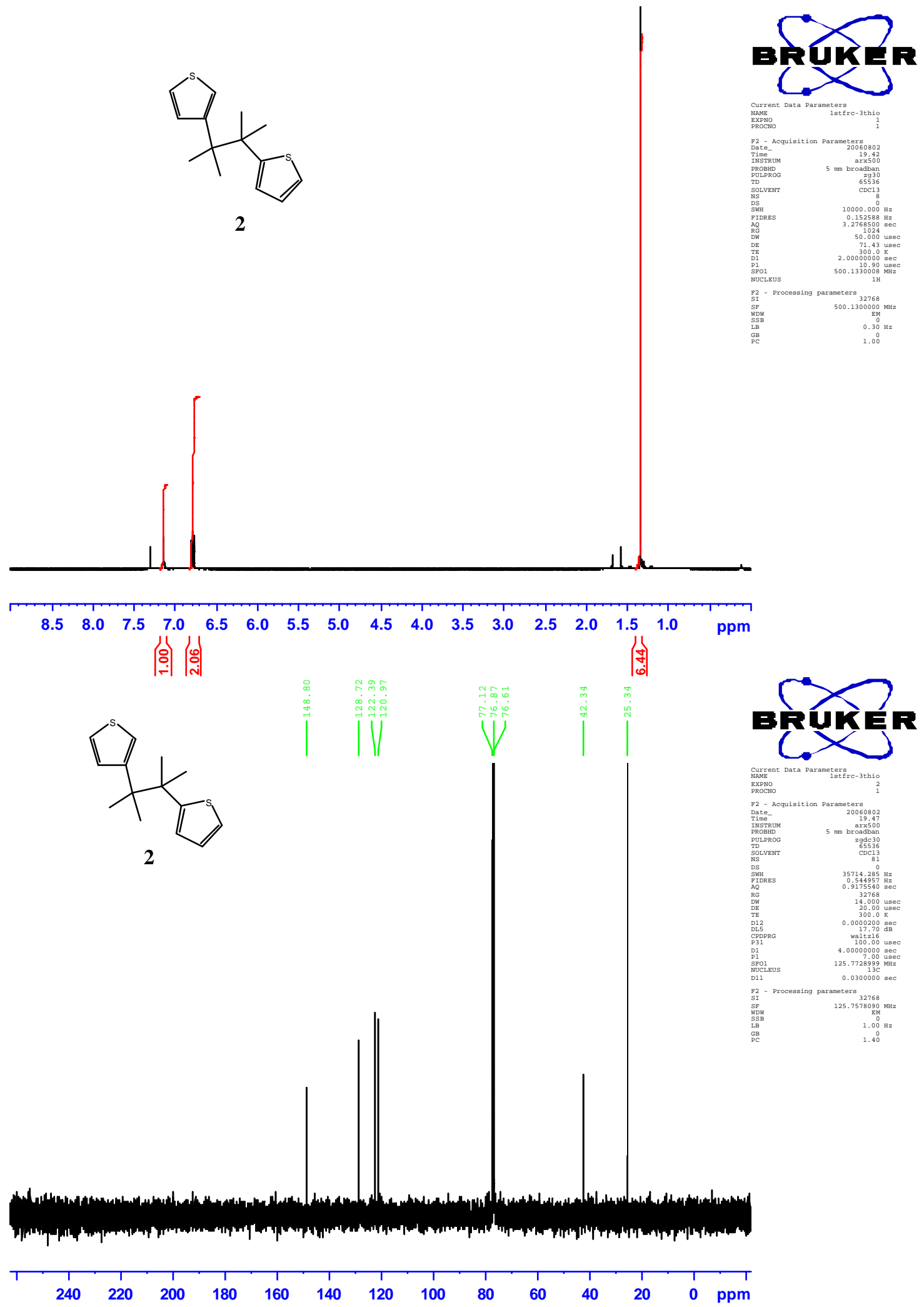
Photographs of polycrystalline powders of ketone 1 before (left) and after (right) exposure to light $>300 \mathrm{~nm}$ for a period of 48 hours and $8 \%$

conversion. A significant darkening on the samples was always observed, which prevents any further reaction. NMR spectroscopy of the blackened sample showed peaks corresponding to 1 and $\mathbf{2}$ exclusively.

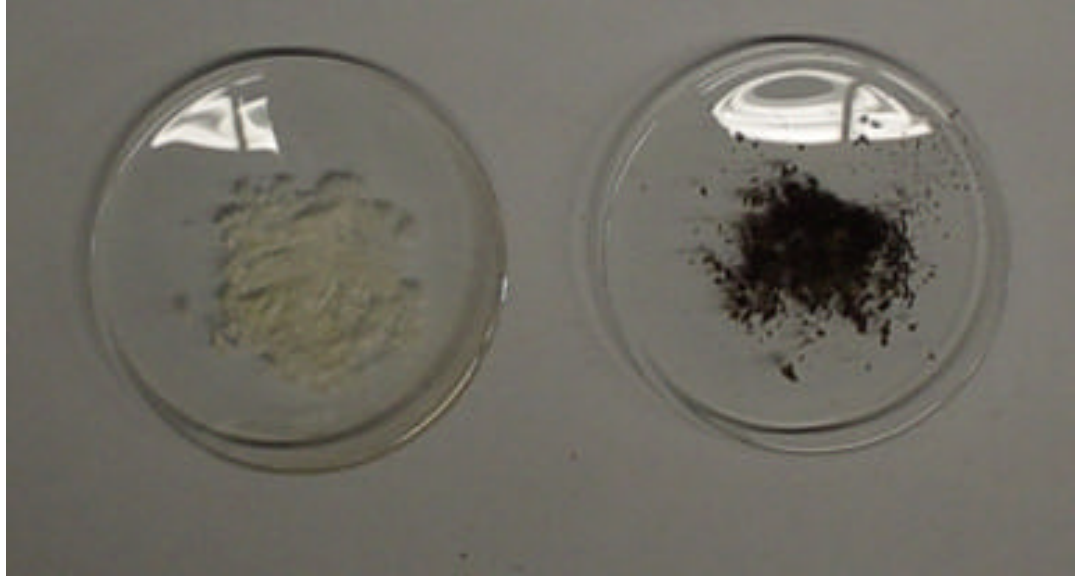




\section{X-Ray Powder Diffraction}

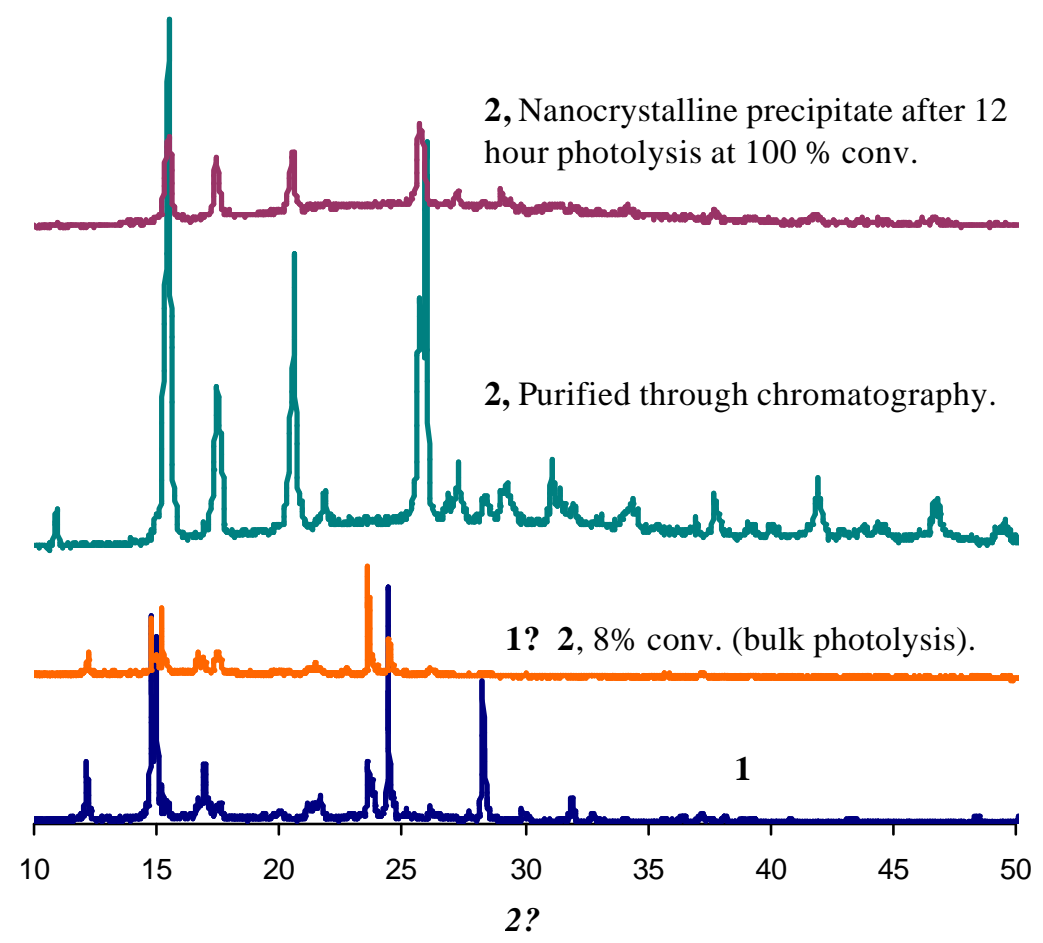

XRPD Experiments provide evidence of the high cristallinity arising from samples of $\mathbf{1}$ (white powder, trace shown in blue). Samples of the incomplete transformation (8\% conv.) lose some of the long-range order shown in 1, as suggested by the disappearance of peaks 2 ? $>25^{\circ}$ (trace shown in orange). Decarbonylation product 2 purified by column chromatography also showed a high degree of cristallinity (shown in green). The precipitate collected from the nanocrystalline suspension at $100 \%$ conv. shows peaks that match those of pure 2 (purple). 


\section{DSC trace for 1}

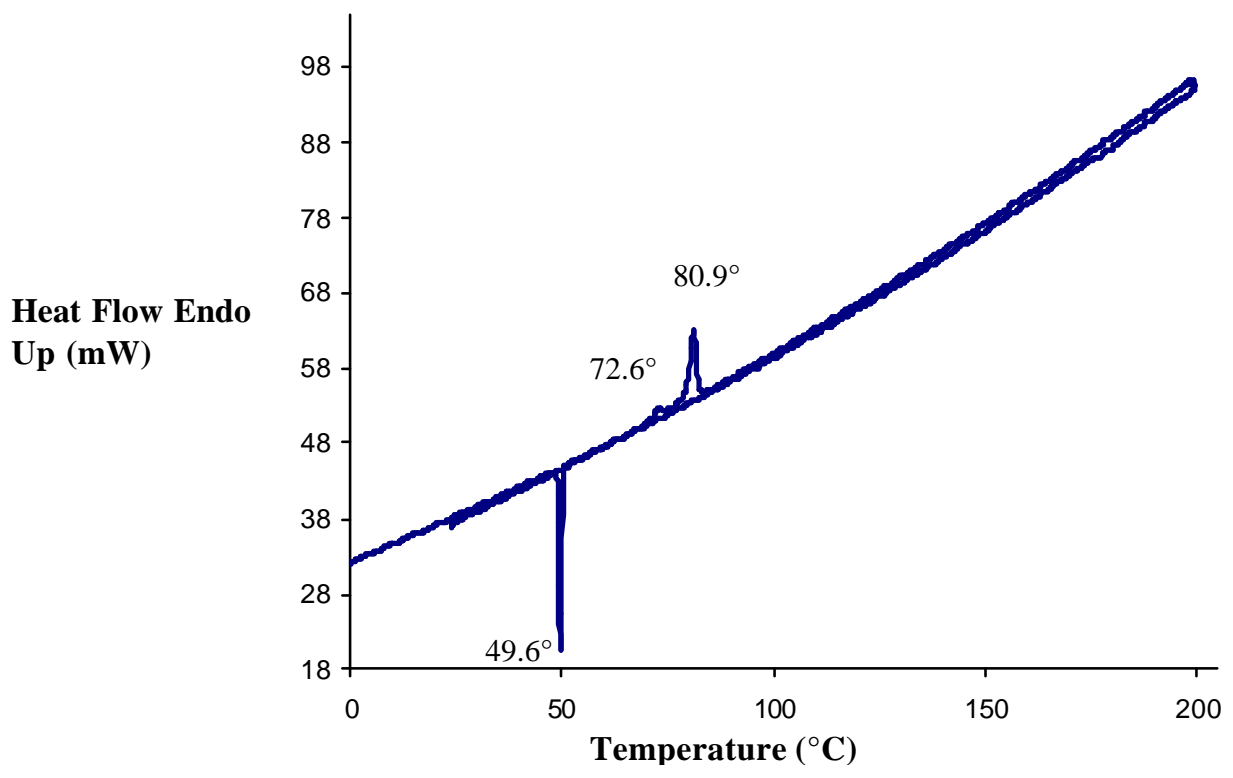

Parameters used: Hold for $2.0 \mathrm{~min}$ at $25.0^{\circ} \mathrm{C}$; Heat from $25.0^{\circ}$ to $200.0^{\circ}$ at $15.0^{\circ} / \mathrm{min}$; Hold $1.0 \mathrm{~min}$ at $200.0^{\circ}$; Cool to $0.0^{\circ}$ at $15.0^{\circ} / \mathrm{min}$; Hold $1.0 \mathrm{~min}$ at $0^{\circ}$.

DSC experiments on $\mathbf{1}$ show a small phase transition at $72.6^{\circ}$ followed by melting of the sample at $81^{\circ}$. Recrystallization occurs at $50^{\circ} \mathrm{C}$ upon cooling.

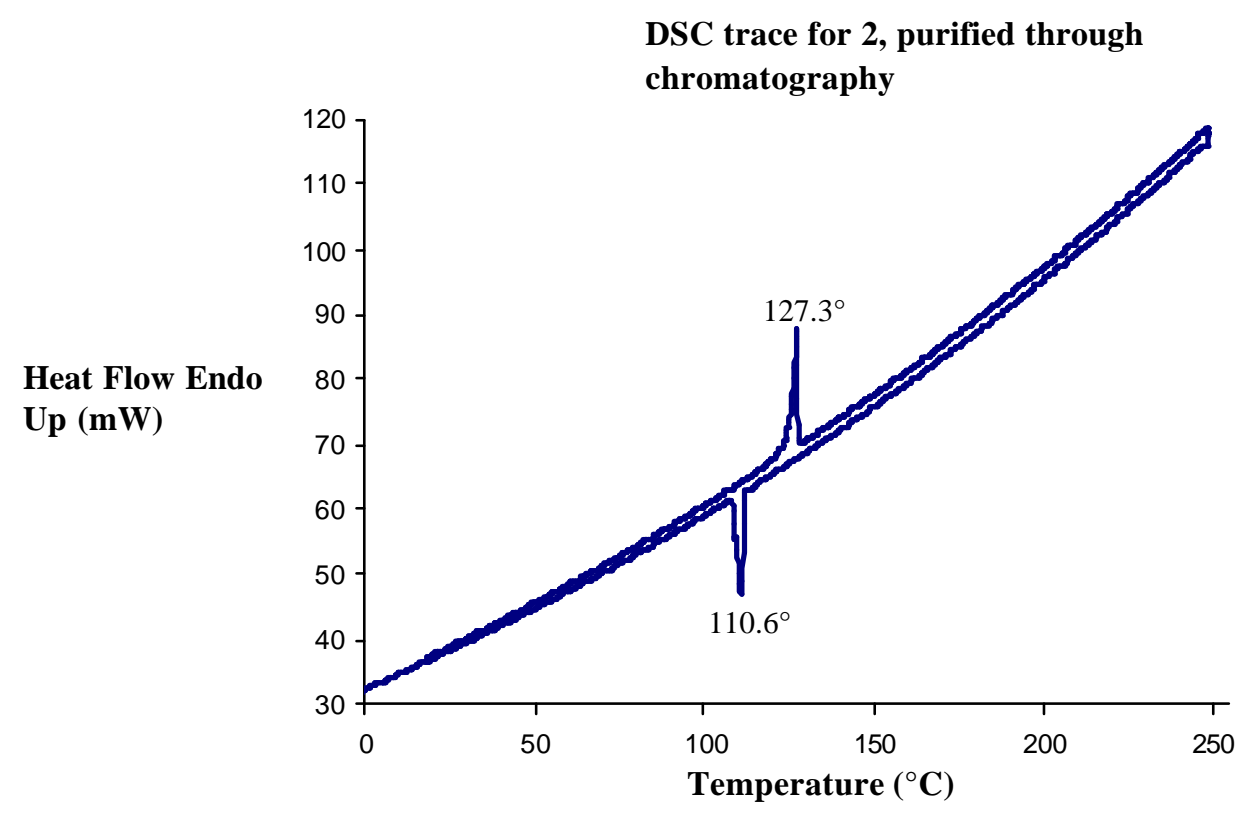

Parameters used: Hold for $2.0 \mathrm{~min}$ at $20.0^{\circ} \mathrm{C}$; Heat from $20.0^{\circ}$ to $250.0^{\circ}$ at $10.0^{\circ} / \mathrm{min}$; Hold $1.0 \mathrm{~min}$ at $250.0^{\circ}$; Cool to $0.0^{\circ}$ at $15.0^{\circ} \mathrm{min}$; Hold $2.0 \mathrm{~min}$ at $0^{\circ}$.

DSC experiments on 2 show melting of the sample at $127^{\circ}$ and consequent recrystallization at $110^{\circ} \mathrm{C}$ upon cooling. 
DSC trace for 2, nanocrystalline precipitate after 12 hour hv at $100 \%$ conv.

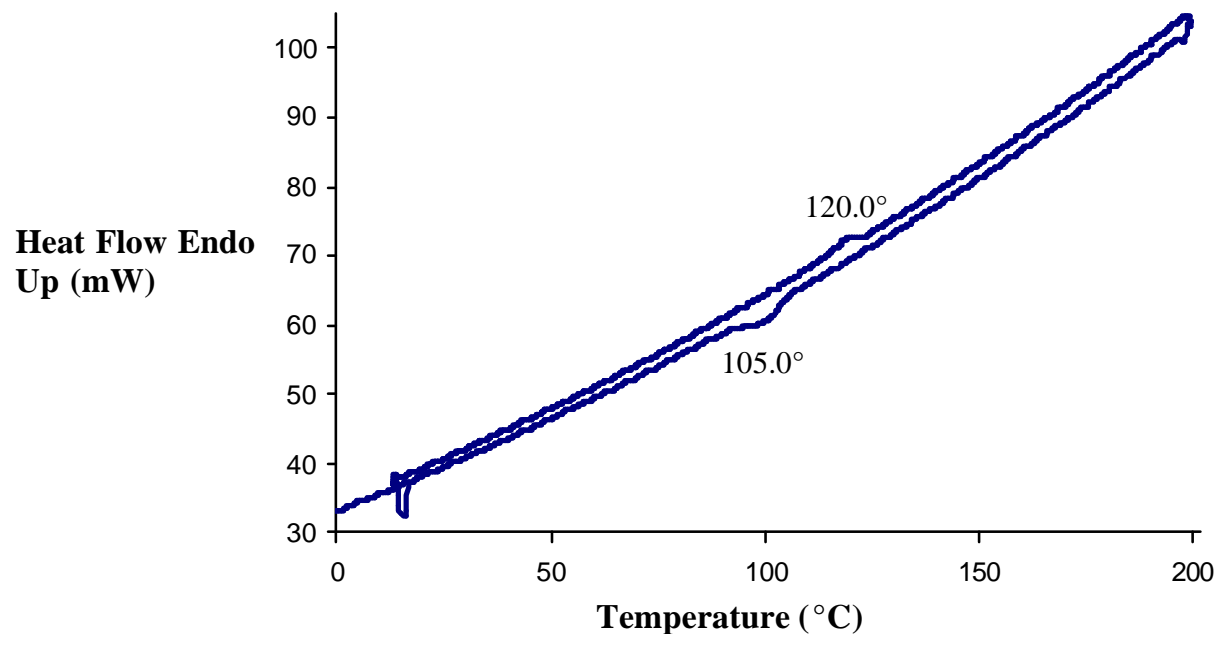

Parameters used: Hold for $2.0 \mathrm{~min}$ at $15.0^{\circ} \mathrm{C}$; Heat from $15.0^{\circ}$ to $200.0^{\circ}$ at $10.0^{\circ} / \mathrm{min}$; Hold $1.0 \mathrm{~min}$ at $200.0^{\circ}$; Cool to $0.0^{\circ}$ at $15.0^{\circ} \mathrm{min}$; Hold $2.0 \mathrm{~min}$ at $0^{\circ}$.

DSC experiments after the transformation of $\mathbf{1}$ ? 2 to $100 \%$ conversion in a nanocrystalline suspensions of $\mathbf{1}$ using SDS/ $\mathrm{H}_{2} \mathrm{O}$ as media. The trace for $\mathbf{2}$ shows a small depression to a melting of $120^{\circ}$ and a recrystallization of $105^{\circ} \mathrm{C}$.

${ }^{1}$ Resendiz, M. J. E.; Garcia-Garibay, M. A. Org. Lett. 2005, 7,371.

${ }^{2}$ Braverman, S.; Duar, Y.; Freund, M. Isr. J. Chem. 1985, 26, 108. 